\title{
Critique of the Analysis of UpToDate.com on the Treatment of Painful Vertebral Compression Fractures: Time to Update UpToDate
}

\author{
D.P. Beall, W.P. McRoberts, S.H. Berven, J.T. Ledlie, S.M. Tutton, and B.P. Parsons
}

\begin{abstract}
SUMMARY: The treatment of painful vertebral compression fractures has changed substantially since the introduction of vertebroplasty in the mid-1980s and balloon kyphoplasty in the late 1990s. Both procedures were widely accepted with the vertebral fractures treated reaching 150,000 per annum in 2009 prior to the publication of 2 randomized controlled trials comparing vertebroplasty with a sham treatment published in the New England Journal of Medicine in August 2009. Since then, there has been a flood of information on vertebral augmentation and balloon kyphoplasty. It is worth evaluating this information especially because it relates to current recommendations that are often followed blindly by medical and administrative groups unfamiliar with either the procedure or the high level of evidence surrounding vertebral augmentation. To streamline the evaluation of some current recommendations, we limited the analysis to the recommendations found on UpToDate.com. This Web site is an evidence-based, peer-reviewed source of information available for patients, doctors, health insurance companies, and population-based medical decision-making.
\end{abstract}

ABBREVIATIONS: $B$ BP = balloon kyphoplasty; NSM = nonsurgical management; $\mathrm{VA}=$ vertebral augmentation; $\mathrm{VCF}=$ vertebral compression fracture; $\mathrm{VP}=$ vertebroplasty

I he treatment of painful vertebral compression fractures (VCFs) has changed substantially since the introduction of vertebroplasty in the mid-1980s. ${ }^{1}$ The advent of balloon kyphoplasty in the late 1990 s represented a new variation of the procedure by using balloons to reduce the vertebral fracture and create a void within the vertebral body. ${ }^{2}$ Both procedures were widely accepted with vertebral fractures treated reaching 150,000 per annum in 2009 before the publication of 2 randomized controlled trials comparing vertebroplasty with a sham treatment published in the New England Journal of Medicine in August 2009. ${ }^{3-5}$

The publication of the trials generated a substantial controversy because the results seemed to fly in the face of clinical experience; consequently, numerous societies and physician groups issued statements commenting on the conclusions of the studies. The Society of Interventional Radiology ${ }^{6}$ and the North American

Received June 19, 2014; accepted after revision June 30.

From Radiology Services (D.P.B.), Clinical Radiology of Oklahoma, Musculoskeletal Imaging and Interventional, Oklahoma City, Oklahoma; Interventional Spine and Pain Medicine (W.P.M.), Holy Cross Hospital, Fort Lauderdale, Florida; Department of Orthopaedic Surgery (S.H.B.), University of California San Francisco, San Francisco, California; Tyler Neurosurgery (J.T.L.), Tyler, Texas; Departments of Radiology and Surgery (S.M.T.), Medical College of Wisconsin, Froedtert East Clinic, Milwaukee, Wisconsin; and Department of Radiology (B.P.P.), University of Oklahoma College of Medicine, Edmond, Oklahoma.

Please address correspondence to Douglas P. Beall, MD, Chief of Radiology Services, Clinical Radiology of Oklahoma, Musculoskeletal Imaging and Interventional, 610 NW 14th St, Oklahoma City, OK 73103; e-mail: db@clinrad.org

http://dx.doi.org/10.3174/ajnr.A4095

Spine Society ${ }^{7}$ issued statements commenting on the trials with the Society of Interventional Radiology stating that "based on the ... weakness in the studies and the degree of discordance between the outcomes of these studies, prior studies and experience, we believe it is premature - and possibly incorrect-to conclude that vertebroplasty is no better than a control sham procedure" and the North American Spine Society stating that "[b] eyond the lay press releases which claim 'Vertebroplasty found to be useless for osteoporotic fracture and disk pain,' it is time for cooler heads to prevail. The medical literature thirsts for evidence. The data from these two studies must be considered carefully and thoughtfully.... More practical conclusions should be made based on a thorough and systematic review of all the literature to better define the subgroup of patients for which vertebroplasty might be most appropriate."

Since 2009, a flood of information has discussed vertebral augmentation (VA), a term that includes vertebroplasty (VP) and balloon kyphoplasty (BKP). This information provides valuable insight into the treatment of patients with osteoporotic VCFs. It is worth evaluating this information especially because it relates to current recommendations that are often followed blindly by medical and administrative groups unfamiliar with either the VA procedures or the high level and unpresented body of evidence surrounding VA.

To streamline the evaluation of some current recommendations, we limited the analysis to the recommendations found on 
UpToDate.com. This Web site is an evidence-based, peer-reviewed source of information available for patients, doctors, health insurance companies, and population-based medical decision-making. Taking the recommendations point-by-point from the Web site and comparing them with evidence-based information found in the medical literature will simplify the process.

\section{UpToDate.com on Pain Relief Benefits of Vertebroplasty}

Short-term placebo-controlled (sham procedure) trials of vertebroplasty in patients with osteoporotic compression fractures have not shown a significant benefit in reducing pain. ${ }^{8,9}$ Thus, we do not recommend vertebroplasty or kyphoplasty for the treatment of osteoporotic compression fractures.

Evidence-Based Information. The authors are basing their recommendation not to treat on 2 trials published in $2009 .^{4,5}$ These articles are vertebroplasty articles only, but the authors extrapolated their recommendation to BKP as well, it being a different procedure.

There are 1587 vertebral augmentation articles in the English language. The most recent meta-analysis published in 2012 is the first one of only level 1 and 2 data, and it evaluated 27 studies, including 8 randomized studies. ${ }^{10}$ The authors concluded after analyzing this body of literature in great detail that both VP and BKP provide significant pain relief and a 50\% reduced rate of additional fracture over nonsurgical management. They also concluded that BKP has better anatomy restoration and may be more beneficial than VP for improving quality of life and disability.

A recommendation against a procedure that has very strong support by a large body of high-quality literature is not a logical recommendation, but to extrapolate that recommendation to a procedure that has even greater support in the literature is a non sequitur.

\section{UpToDate.com on Pain Relief and Patient Selection}

In unblinded randomized trials comparing vertebroplasty with pain management, there was greater improvement in pain immediately after vertebroplasty (1 day) but not at 2 weeks, ${ }^{11} 3$ months, ${ }^{12}$ or 12 months. ${ }^{13}$ In 1 trial, the improvement in pain after vertebroplasty was significant at 1 day, 1 month, and 1 year. ${ }^{14}$ However by the 1-month and 1-year time points, the between-group differences in the reduction in mean pain score $(-2.6$ and -2.0 , respectively) were of uncertain clinical significance. In addition, more than half of the patients who initially qualified for the study had spontaneous reduction or resolution of pain (mean pain score, $<5$ ) during screening and therefore were not eligible for inclusion in the study.

Evidence-Based Information. The authors stated that the VERTOS trial, ${ }^{11}$ a randomized controlled trial investigating percutaneous vertebroplasty with optimal pain medication treatment, showed no greater improvement of pain after 2 weeks. They then compared this pain measurement with 2 additional time points ( 3 months and 12 months) in 2 studies different from the VERTOS trial. This comparison has too much heterogeneity to allow an appropriate comparison, and the "snapshot in time" implication that there was no difference in pain levels is not what the VERTOS trial concluded. Rather, the VERTOS authors reported that "pain relief and improvement of mobility, function, and stature after VP is immediate and significantly better in the short term compared with medication treatment." ${ }^{11}$ The additional 2 studies by Rousing et $\mathrm{al}^{15,16}$ were 3- and 12-month follow-ups of the same patients. The authors of UpToDate.com did not mention that in these studies, the pain score before and after the operation in the VP group was 7.9 and 2.0, respectively, a significant decrease, and that assessment of back pain 1 month after discharge from the hospital showed a significantly lower Visual Analog Scale score in the VP group over the conservative group. The referenced studies are also small with a combined total of 133 patients and especially small compared with the much more highly regarded VERTOS II trial with 202 patients, which found consistent and significant pain relief at 6 different measurements at the conclusion of the study at a year. ${ }^{14}$

A recent meta-analysis on VP, which was the first to include all the available prospective evidence, including 9 prospective controlled trials (6 of which were randomized controlled trials), concluded that compared with nonsurgical management (NSM), VP was more effective in relieving pain and in improving the quality of life for patients with VCFs. ${ }^{17}$ This meta-analysis was also substantially larger, quadrupling the sample size compared with previous meta-analysis.

A comment was made by the UpToDate.com authors that "more than half of the patients who initially qualified for the study had spontaneous reduction or resolution of pain (mean pain score $<5$ ) during screening and therefore were not eligible for inclusion in the study." ${ }^{17}$ We believe that this is an entirely appropriate execution of the inclusion/exclusion criteria. VCFs can heal and often do, but when they are present, these fractures tend to cause pain that most patients would rate at least a 6 or 7 of $10 .^{18}$ When patients are included in fracture assessments that have fewer than 6 of 10 levels of pain, the pain is likely not coming from the fracture. The INVEST trial, investigational vertebroplasty safety and efficacy trial, previously referenced by the UpToDate.com authors had a pain level of $\geq 3$ as an inclusion criterion, which could certainly have allowed many patients to be evaluated for the treatment of their fractures who did not have pain related to the fracture at all. Additionally, in this trial, they screened 1812 patients to enroll 131. This trial has a far greater discrepancy between screened and enrolled patients than the VERTOS trial and could certainly give rise to significant selection bias.

\section{UpToDate.com on Timing of Vertebral Augmentation}

VP and BKP are performed in an outpatient setting, though the optimal timing related to fracture acuity is unclear. ${ }^{19,20}$

Evidence-Based Information. A meta-analysis of all of the level 1 and 2 data shows that surgical intervention within the first 7 weeks yielded greater pain reduction than VCFs treated later. ${ }^{10}$ The UpToDate.com authors referred to an article by Ledlie and Renfro ${ }^{19}$ in regard to the timing of VP and BKP, but according to Dr Ledlie, the article does not address the timing of BKP and only the average age of the fractures in the series was reported. He also stated that this was a report on an historical series and not a recommendation for the timing of BKP.

The Kaufmann et $\mathrm{al}^{20}$ reference in support of the UpToDate 
statement actually concluded that "VP is a highly efficacious therapy for relief of pain and improvement in mobility, regardless of fracture age." The authors also noted that the longer the fracture had been present, the greater was the need for postprocedural anesthesia. The information determined is that painful VCFs are well-treated regardless of age and that the sooner they are treated, the less the requirement will be for postoperative pain medication.

\section{UpToDate.com on Short- and Long-Term Benefits}

The potential short-term benefit for both procedures is improvement in pain, whereas potential long-term benefits include prevention of recurrent pain at the treated levels, limitation or reversal of height loss and spinal deformity, and improved functional capability.

Evidence-Based Information. These assertions are not referenced but state that VP and BKP provide short-term benefits in pain. If all of the best level 1 data that follow a patient $>6$ months are analyzed, the benefit is consistent and persistent for the treated patients up to 2 years. ${ }^{10,11,17}$ The long-term benefits are more difficult to accurately characterize because these patients are not typically followed for $>2$ years, but on the basis of current information, if the patient does not have an additional fracture or other spine injury, their pain relief should be durable.

\section{UpToDate.com on Randomized Controlled Trials on Vertebroplasty}

In 2 short-term, blinded trials comparing vertebroplasty with a sham procedure, there was no immediate or delayed benefit of vertebroplasty. ${ }^{4,5}$ One of these trials compared vertebroplasty with a simulated procedure without cement in 131 patients who had 1-3 painful osteoporotic VCFs. ${ }^{4}$ The primary outcomes were pain intensity during the previous 24 hours and disability, measured by the modified Roland-Morris Disability Questionnaire. The improvement in pain and disability scores was similar in both groups at all time points (3 days, 2 weeks, 1 month). In both groups, the greatest improvement occurred within 3 days of the procedure and was maintained at 1 month.

In these 2 trials, patients assigned to the sham procedures received the same subcutaneous and periosteal anesthetic as those assigned to the full vertebroplasty procedure. The anesthetic, rather than the vertebroplasty procedure itself, may account for some of the immediate pain relief noted in unblinded trials. ${ }^{4,16}$

On the basis of the available data, we do not recommend vertebroplasty for pain reduction in patients with osteoporotic compression fractures.

Evidence-Based Information. The UpToDate.com authors focused on 2 randomized controlled trials published in 2009., There is no mention of an analysis of the total body of literature for making a treatment decision. As mentioned above, a metaanalysis published in 2012 was the first to include all available prospective evidence, including 6 randomized controlled trials. ${ }^{4,5}$ This meta-analysis concluded that compared with NSM, vertebroplasty was more effective in relieving pain and in improving the quality of life for patients with VCFs. We believe that recom- mendations should be based on all of the available high-quality data, not just 2 small selected studies.

In regard to the 2 randomized controlled trials published in 2009 , these studies are highly controversial and have generated a large amount of discussion. Most of the issues focus on the execution of these 2 trials. Some of the primary criticisms were that the INVEST trial was underpowered (target enrollment was 250 versus the actual enrollment of 131) and that both studies had prominent selection bias. The crossover of patients in the INVEST trial was far greater for those patients crossing over from sham to VP (51\%) compared with vice versa (13\%). The clinical and imaging diagnostic criteria for inclusion were very different from those in most randomized controlled trials, with patients having a pain score of $\geq 3$ on the Visual Analog Scale being eligible for inclusion, and there was no requirement for MR imaging or nuclear bone scanning for diagnosing the VCFs. There was also no description of a clinical examination used to determine whether the pain came from the VCF itself or from another problem, and the trial of Buchbinder et $\mathrm{al}^{5}$ assessed "overall pain" rather than spine-related pain, undermining the validity of the measurement in this population replete with potentially comorbid painful conditions. There was also criticism that the INVEST trial was not a true sham, with $63 \%$ of the patients receiving sham treatment correctly guessing that their treatment, and the injection was performed with a paraspinal injection of local anesthetic, which has been used to successfully palliate patients' pain from VCFs for up to 8 weeks. ${ }^{21}$ Despite all of these limiting factors, if the same response rate for the 131 patients had been obtained on the originally intended 250 patients, VP would have been found to be significantly better than sham treatment at a $P$ value of $<.01$. Despite the low enrollment of only 131 patients, if only 1 patient had reported a different response (ie, a favorable response in the VP group or an unfavorable response in the sham group), VP would have been found to be significantly better than a sham, with a $P$ value of $<.04$. Given the near-equivocal nature of this information, it is an inappropriate trial on which to base significant population-based recommendations and, in our opinion, the quality of the assessment in these trials was far less than in other trials that had a greater number of patients. ${ }^{8,9,14,16}$

\section{UpToDate.com on Kyphoplasty}

Data from randomized trials are limited. In the largest trial to date, 300 patients with 1-3 acute vertebral fractures were randomly assigned to balloon kyphoplasty versus nonsurgical care (not a sham procedure as in the above vertebroplasty trials). ${ }^{12}$ After 1 month, patients assigned to kyphoplasty had greater improvement in the Short-Form 36 physical component summary scale, a validated quality of life measurement. However, after 12 months, the difference in improvement between the 2 groups was no longer significant.

Evidence-Based Information. The authors stated that randomized controlled trials on BKP are limited. Of the 27 articles identified by Papanastassiou et $\mathrm{al}^{10}$ in their summary of all level 1 and 2 data on VA, 18 of the studies involved BKP. All these studies by definition included $>20$ patients, and the BKP articles included the FREE trial, efficacy and safety of balloon kyphoplasty compared with non-surgical care for vertebral compression fracture, 
with 300 patients, and a trial comparing BKP and VP with 100 patients. ${ }^{12,22}$ The conclusion of Papanastassiou et al regarding BKP was that it decreased pain to a greater degree than VP (5.07 versus 4.55 points on the Visual Analog Scale) and resulted in significantly better improvement in the quality of life than both VP and NSM. This meta-analysis was taken from 1587 articles on vertebral augmentation, more articles than in any other area of spinal medicine. If the authors' contention is that the trials are limited for BKP, then it would follow that there is no other area of the spine that had anything but limited information. It is our contention that there is more than adequate information on which to base a decision that BKP is effective.

The UpToDate.com authors also stated that significant differences in Short-Form 36 were only short-lived, not significant after 12 months, but they did not mention any other parameters measured, ignoring the conclusion of the authors that reduction in pain, EQ-5D (a measure of health status), quality of life, patient satisfaction, and kyphotic angulation remain statistically significant at all time points throughout the 2 years measured. It is also troubling that the authors of UpToDate.com singled out the lack of statistical significance of a single time point in the Short-Form 36 physical component summary when all other time points measured up to a year were significant and all of the time points of the Short-Form 36 Bodily Pain Scale throughout the entire study were significant.

\section{UpToDate.com on Adverse Effects of VP and BKP}

Vertebroplasty and kyphoplasty are not without risk. Shortterm complications occur predominantly because of extravasation of the cement and may include increased pain and damage from heat or pressure to the spinal cord or nerve roots, ${ }^{22}$ and rarely cement embolization. ${ }^{23}$ Extravasation has been reported in $11 \%-73 \%$ of vertebroplasty procedures, ${ }^{24}$ and less commonly with kyphoplasty.

Evidence-Based Information. The authors stated that short-term complications occurring from cement extravasation may occur from heat producing damage to the nerve roots or spinal cord, and they referenced an article from Watts et al, ${ }^{22}$ who stated directly that "theoretically, local heat might damage adjacent tissues because of the exothermic reaction, but the surrounding vascularized tissues, particularly the dura, act to reduce local heat effects. Local tissue damage has been reported only anecdotally." This finding has remained true with time, and exothermic damage to neural elements and other structures is either very rare or nonexistent. A recent randomized controlled trial of 256 patients examined the differences between traditional polymethylmethacrylate (bone cement) and Cortoss (Stryker, Kalamazoo, Michigan), an injectable, combeite glass ceramic tri-resin polymer with little to no exothermic reaction. The study showed no difference in complication rates, no evidence of adverse exothermic events with bone cement, and no difference between cements in the reduction of the patient pain levels. ${ }^{13}$

The authors also characterized cement embolization and extravasation as adverse effects. A better description reveals embolization and extravasation as extremely common with embolization occurring in 5\%-23\% of all patients and extravasation in up to $73 \%$ as stated above. ${ }^{23-27}$ Most important, however, is the point that most embolisms and extravasation are neither symptomatic or adverse. A review of all of the level 1 and 2 data shows that most studies did not either report or encounter any serious adverse events. Overall, the literature suggests that both procedures had safe serious adverse event profiles with occasional case reports of symptomatic cement extravasation in the VP arm. ${ }^{28-35}$

The risk of performing VA should be balanced with the risk of withholding the procedure because these patients are typically debilitated and have a mortality rate of 8.6 times that of agematched controls and have a $40 \%$ greater mortality after 8 years. ${ }^{36,37}$ In the first longitudinal, population-based comparison of mortality risk between surgical and nonsurgical groups, a Medicare dataset from 2005 to 2008 comprising 858,978 patients with VCFs was analyzed. ${ }^{38}$ This included 119,253 patients treated with BKP, 63,693 patients treated with VP, and the remainder treated with NSM. The findings at the 4-year follow-up showed that the VA treatment group was $37 \%$ less likely to die than the NSM group and that the adjusted life expectancy was $85 \%$ greater for the VA group. The adjusted life expectancy for the BKP was greater than that of VP and was increased $115 \%$ compared with the NSM group. Overall the median life expectancy was increased between 2.2 and 7.3 years across all treated groups compared with nonsurgical management. A retrospective review of the treatment of refractory osteoporotic VCFs by Gerling et al, ${ }^{39}$ in which treatment with VA was compared with NSM in a hospital setting found a significant survival advantage $(P<.001)$ for patients treated with VA over those patients treated with NSM, regardless of comorbidities, age, or the number of fractures diagnosed at the start date.

\section{UpToDate.com on Adjacent-Level Fractures}

Two retrospective reviews of patients treated with vertebroplasty found a high rate of new vertebral fractures. ${ }^{40-42}$ In 1 report of 177 patients, 22 patients developed 36 new vertebral body fractures. Of the 36 fractures, $67 \%$ involved vertebrae adjacent to a previously treated level and $67 \%$ occurred within 30 days after the initial treatment. ${ }^{32}$ In another study of 432 patients treated with vertebroplasty, 84 patients had new vertebral fractures occurring within 4 months of the procedure. ${ }^{41}$

Evidence-Based Information. If all of the level 1 and 2 data on VA are analyzed rather than focusing on particular studies, the adjacent-level fracture rate for those patients treated with VA was $11 \%$ compared with $22 \%$ for those patients treated with NSM. ${ }^{10}$ The rate of adjacent-level fractures in untreated patients was 20\%. ${ }^{40,43}$ Not only does there appear to be no increased risk of adjacentlevel fractures, but there is also very strong supporting evidence that treatment with VA reduces the rate of adjacent-level fractures by half. ${ }^{10}$

\section{CONCLUSIONS}

Substantial scientific contributions to the English literature on vertebral augmentation rival nearly any other topic in the spine. If the highest quality portion of that literature is analyzed, the conclusions that can be drawn are that vertebral augmentation was significantly better than nonsurgical management for decreasing pain and if the fracture was treated in the first 7 weeks, the pain reduction was better. This analysis also showed significantly fewer 
additional fractures for those patients treated with vertebral augmentation rather than those treated with nonsurgical management, and those patients treated with kyphoplasty had a significantly better improvement in their quality of life than those treated with vertebroplasty.

Most of the best contributions to the literature have been relatively recent, and many of the analyses and recommendations have been based on older literature. The data show significantly higher mortality rates in those treated with nonsurgical management compared with those patients treated with vertebral augmentation; these findings emphasize the importance of offering the treatment most likely to benefit the patient. The data show these benefits to be pain reduction, fewer additional fractures, and improved quality and length of life. If all of these factors are taken into consideration, it appears that the information on UpToDate is out of date.

Disclosures: Douglas P. Beall—RELATED: Consulting Fee or Honorarium: Spineology; UNRELATED: Board Membership: Medtronic, Benvenue; Consultancy: Medtronic, Dfine, Osseon, Lilly, Smith and Nephew, VertiFlex, Synthes, Alphatech Spine, Benvenue, Convatec, Integral Spine Solutions, Medical Metrics; Payment for Lectures (including service on Speakers Bureaus): Medtronic, Dfine, Osseon, Lilly, Smith and Nephew, VertiFlex, Synthes, Alphatech Spine, Benvenue, Convatec, Integral Spine Solutions, Medical Metrics; Payment for Development of Educational Presentations: Medtronic, Benvenue; Stock/Stock Options: Spineology; Travel/Accommodations/Meeting Expenses Unrelated to Activities Listed: Medtronic; Other: Medtronic, Dfine, Osseon, Lilly, Smith and Nephew, VertiFlex, Synthes, Alphatech Spine, Benvenue, Convatec, Integral Spine Solutions, Medical Metrics. Sigurd H. Berven—UNRELATED: Board Membership: Globus Medical, Medtronic Interventional; Grants/Grants Pending: National Institutes of Health, ${ }^{*}$ Orthopaedic Research and Education Foundation, ${ }^{*}$ AOSpine, ${ }^{*}$ Globus Medical*; Payment for Lectures (including service on Speakers Bureaus): Biomet, DePuy, Globus, Medtronic, Stryker; Royalties: Medtronic; Stock/Stock Options: Simpirica, Providence Medical. Sean M. Tutton-UNRELATED: Consultancy: Benvenue. William Porter McRoberts—UNRELATED: Board Membership: Medtronic, St. Jude, Comments: I sit on the scientific advisory board of these 2 companies; Consultancy: St. Jude, Medtronic, Axonics, Bioness, Gore Technologies, Spinal Modulation, Comments: I provide scientific advice to these companies; Payment for Lectures (including service on Speakers Bureaus): St. Jude, Comments: I provide medical education for this company; Payment for Development of Educational Presentations: St. Jude, Comments: I help develop education materials surrounding neuromodulation. Jon T. Ledlie-UNRELATED: Board Membership: Alphatec Scientific Advisory Board; Consultancy: Medtronic; Payment for Lectures (including service on Speakers Bureaus): Medtronic; Stock/ Stock Options: Phygen stock; Phygen was bought by Alphatec and the stock converted to Alphatec; OTHER RELATIONSHIPS: past member of Kyphon Scientific Advisory Board. *Money paid to the institution.

\section{REFERENCES}

1. Galibert P, Deramond H, Rosat $\mathrm{P}$, et al. Preliminary note on the treatment of vertebral angioma by percutaneous acrylic vertebroplasty [in French]. Neurochirurgie 1987;33:166-68

2. Voggenreiter G. Balloon kyphoplasty is effective in deformity correction of osteoporotic vertebral compression fractures. Spine (Phila Pa 1976) 2005;30:2806-12

3. Millennium Research Group. Global Markets for Minimally Invasive Vertebral Compression Fracture Treatments 2010. December 30, 2009. http://www.marketresearch.com/Millennium-Research-Groupv648/Global-Minimally-Invasive-Vertebral-Compression-2731438/. Accessed February 20, 2013

4. Kallmes DF, Comstock BA, Heagerty PJ, et al. A randomized trial of vertebroplasty for osteoporotic spinal fractures. $N \mathrm{Engl} \mathrm{J} \mathrm{Med}$ 2009;361:569-79

5. Buchbinder R, Osborne RH, Ebeling PR, et al. A randomized trial of vertebroplasty for painful osteoporotic vertebral fractures. $N$ Engl J Med 2009;361:557-68

6. Society of Interventional Radiology. Society of Interventional Radiology commentary on vertebroplasty and the August studies in the
New England Journal of Medicine. http://www.sirweb.org/misc/ Noridian/Commentary_SIR_vertebroplasty.pdf. Published November 24, 2009. Accessed February 15, 2013

7. North American Spine Society. Newly released vertebroplasty RCT's: a tale of two trials. http://www.spine.org/Documents/NASS Comment_on_Vertebroplasty.pdf. Published October 13, 2009. Accessed March 5, 2013

8. Kasperk C, Hillmeier J, Nöldge G, et al. Treatment of painful vertebral fractures by kyphoplasty in patients with primary osteoporosis: a prospective nonrandomized controlled study. J Bone Miner Res 2005;20:604-12

9. Komp M, Ruetten S, Godolias G. Minimally invasive therapy for functionally unstable osteoporotic vertebral fracture by means of kyphoplasty: prospective comparative study of 19 surgically and 17 conservatively treated patients. J Miner Stoffwechs 2004; 11(suppl 1):13-15

10. Papanastassiou ID, Phillips FM, Meirhaeghe JV, et al. Comparing effects of kyphoplasty, vertebroplasty, and non-surgical management in a systematic review of randomized and non-randomized controlled studies. Eur Spine J 2012;21:1826-43

11. Voormolen MH, Mali WP, Lohle PN, et al. Percutaneous vertebroplasty compared with optimal pain medication treatment: shortterm clinical outcome of patients with subacute or chronic painful osteoporotic vertebral compression fractures. The VERTOS study. AJNR Am J Neuroradiol 2007;28:555-60

12. Wardlaw D, Cummings SR, Van Meirhaeghe J, et al. Efficacy and safety of balloon kyphoplasty compared with non-surgical care for vertebral compression fracture (FREE): a randomised controlled trial. Lancet 2009;373:1016-24

13. Bae H, Hatten HP Jr, Linovitz R. A prospective randomized FDAIDE trial comparing Cortoss with PMMA for vertebroplasty: a comparative effectiveness research study with 24-month follow-up. Spine (Phila Pa 1976) 2012;37:544-50

14. Klazen CA, Lohle PN, de Vries J, et al. Vertebroplasty versus conservative treatment in acute osteoporotic vertebral compression fractures (Vertos II): an open-label randomised trial. Lancet 2010;376:1085-92

15. Rousing R, Andersen MO, Jespersen SM, et al. Percutaneous vertebroplasty compared to conservative treatment in patients with painful acute or subacute osteoporotic vertebral fractures: threemonths follow-up in a clinical randomized study. Spine (Phila $\mathrm{Pa}$ 1976) 2009;34:1349-54

16. Rousing R, Hansen KL, Andersen MO, et al. Twelve-months follow-up in forty-nine patients with acute/semiacute osteoporotic vertebral fractures treated conservatively or with percutaneous vertebroplasty: a clinical randomized study. Spine (Phila Pa 1976) 2010;35:478-82

17. Shi MM, Cai XZ, Lin T, et al. Is there really no benefit of vertebroplasty for osteoporotic vertebral fractures? A meta-analysis. Clin Orthop Relat Res 2012;470:2785-99

18. Suzuki N, Ogikubo O, Hansson T. The course of acute vertebral body fragility fracture: its effect on pain, disability and quality of life during 12 months. Eur Spine J 2008;17:1380-90

19. Ledlie JT, Renfro MB. Kyphoplasty treatment of vertebral fractures: 2-year outcomes show sustained benefits. Spine (Phila $\mathrm{Pa}$ 1976) 2006;31:57-64

20. Kaufmann TJ, Jensen ME, Schweickert PA, et al. Age of fracture and clinical outcomes of percutaneous vertebroplasty. AJNR Am J Neuroradiol 2001;22:1860-63.

21. Wilson DJ, Owen S, Corkill RA. Facet injections as a means of reducing the need for vertebroplasty in insufficiency fractures of the spine. Eur Radiol 2011;21:1772-78

22. Watts NB, Harris ST, Genant HK. Treatment of painful osteoporotic vertebral fractures with percutaneous vertebroplasty or kyphoplasty. Osteoporos Int 2001;12:429-37

23. Bernhard J, Heini PF, Villiger PM. Asymptomatic diffuse pulmonary embolism caused by acrylic cement: an unusual complication of percutaneous vertebroplasty. Ann Rheum Dis 2003;62:85-86

AJNR Am J Neuroradiol 36:631-36 Apr 2015 www.ajnr.org 
24. Shapiro S, Abel T, Purvines S. Surgical removal of epidural and intradural polymethylmethacrylate extravasation complicating percutaneous vertebroplasty for an osteoporotic lumbar compression fracture. Case report. J Neurosurg 2003;98(1 suppl):90-92

25. Diamond TH, Champion B, Clark WA. Management of acute osteoporotic vertebral fractures: a nonrandomized trial comparing percutaneous vertebroplasty with conservative therapy. Am J Med 2003;114:257-65

26. Choe DH, Marom EM, Ahrar K, et al. Pulmonary embolism of polymethyl methacrylate during percutaneous vertebroplasty and kyphoplasty. AJR Am J Roentgenol 2004;183:1097-102

27. Duran C, Sirvanci M, Aydoğan M, et al. Pulmonary cement embolism: a complication of percutaneous vertebroplasty. Acta Radiol 2007;48:854-59

28. Kim YJ, Lee JW, Park KW, et al. Pulmonary cement embolism after percutaneous vertebroplasty in osteoporotic vertebral compression fractures: incidence, characteristics, and risk factors. Radiology 2009;251:250-59

29. Dong R, Chen L, Gu Y, et al. Improvement in respiratory function after vertebroplasty and kyphoplasty. Int Orthop 2009;33:1689-94

30. Grohs JG, Matzner M, Trieb K, et al. Minimal invasive stabilization of osteoporotic vertebral fractures: a prospective nonrandomized comparison of vertebroplasty and balloon kyphoplasty. J Spinal Disord Tech 2005;18:238-42

31. Pflugmacher R, Kandziora F, Schroder R, et al. Vertebroplasty and kyphoplasty in osteoporotic fractures of vertebral bodies-a prospective 1-year follow-up analysis [in German]. Rofo 2005;177: $1670-76$

32. Pflugmacher R, Taylor R, Agarwal A, et al. Balloon kyphoplasty in the treatment of metastatic disease of the spine: a 2-year prospective evaluation. Eur Spine J 2008;17:1042-48

33. Santiago FR, Abela AP, Alvarez LG, et al. Pain and functional out- come after vertebroplasty and kyphoplasty. A comparative study. Eur J Radiol 2010;75:e108-13

34. Schofer MD, Efe T, Timmesfeld N, et al. Comparison of kyphoplasty and vertebroplasty in the treatment of fresh vertebral compression fractures. Arch Orthop Trauma Surg 2009;129:1391-99

35. Grafe IA, Da Fonseca K, Hillmeier J, et al. Reduction of pain and fracture incidence after kyphoplasty: 1-year outcomes of a prospective controlled trial of patients with primary osteoporosis. Osteoporos Int 2005; 16:2005-12

36. Cauley JA, Thompson DE, Ensrud KC, et al. Risk of mortality following clinical fractures. Osteoporos Int 2000;11:556-61

37. Lau E, Ong K, Kurtz S, et al. Mortality following the diagnosis of a vertebral compression fracture in the Medicare population. J Bone Joint Surg Am 2008;90:1479-86

38. Edidin AA, Ong KL, Lau E, et al. Mortality risk for operated and nonoperated vertebral fracture patients in the Medicare population. J Bone Miner Res 2011;26:1617-26

39. Gerling MC, Eubanks JD, Patel R, et al. Cement augmentation of refractory osteoporotic vertebral compression fractures: survivorship analysis. Spine (Phila Pa 1976) 2011;36:E1266-69

40. Uppin AA, Hirsch JA, Centenera LV, et al. Occurrence of new vertebral body fracture after percutaneous vertebroplasty in patients with osteoporosis. Radiology 2003;226:119-24

41. Trout AT, Kallmes DF, Kaufmann TJ. New fractures after vertebroplasty: adjacent fractures occur significantly sooner. $A J N R$ Am J Neuroradiol 2006;27:217-23

42. Trout AT, Kallmes DF, Layton KF, et al. Vertebral endplate fractures: an indicator of the abnormal forces generated in the spine after vertebroplasty. J Bone Miner Res 2006;21:1797-802

43. Lindsay R, Silverman SL, Cooper C, et al. Risk of new vertebral fracture in the year following a fracture. JAMA 2001;285:320-23 